\title{
Thymic function in the regulation of $T$ cells, and molecular mechanisms underlying the modulation of cytokines and stress signaling (Review)
}

\author{
FENGGEN YAN, XIUMEI MO, JUNFENG LIU, SIQI YE, XING ZENG and DACAN CHEN \\ Department of Dermatology, The Second Affiliated Hospital of Guangzhou University of Chinese Medicine, \\ Guangdong Provincial Hospital of Chinese Medicine, Guangzhou, Guangdong 510120, P.R. China
}

Received August 15, 2016; Accepted May 12, 2017

DOI: $10.3892 / \mathrm{mmr} .2017 .7525$

\begin{abstract}
The thymus is critical in establishing and maintaining the appropriate microenvironment for promoting the development and selection of T cells. The function and structure of the thymus gland has been extensively studied, particularly as the thymus serves an important physiological role in the lymphatic system. Numerous studies have investigated the morphological features of thymic involution. Recently, research attention has increasingly been focused on thymic proteins as targets for drug intervention. Omics approaches have yielded novel insights into the thymus and possible drug targets. The present review addresses the signaling and transcriptional functions of the thymus, including the molecular mechanisms underlying the regulatory functions of $\mathrm{T}$ cells and their role in the immune system. In addition, the levels of cytokines secreted in the thymus have a significant effect on thymic functions, including thymocyte migration and development, thymic atrophy and thymic recovery. Furthermore, the regulation and molecular mechanisms of stress-mediated thymic atrophy and involution were investigated, with particular emphasis on thymic function as a potential target for drug development and discovery using proteomics.
\end{abstract}

\section{Contents}

1. Introduction

2. Molecular mechanisms underlying regulatory $\mathrm{T}$ cell generation in the thymus

Correspondence to: Professor Dacan Chen, Department of Dermatology, The Second Affiliated Hospital of Guangzhou University of Chinese Medicine, Guangdong Provincial Hospital of Chinese Medicine, 111 Dade Road, Guangzhou, Guangdong 510120, P.R. China

E-mail: 4910702@163.com

Key words: thymic function, $\mathrm{T}$ cells, molecular mechanisms, cytokines, stress signaling
3. Effects of cytokines on thymic function

4. Regulation of molecular mechanisms in stress-mediated thymic atrophy and involution

5. Prediction of potential drug targets on the thymus using proteomics

6. Final remarks

\section{Introduction}

The thymus is a bilobed organ located in the superior mediastinum of the thorax, above the heart and behind the sternum. It can be divided into two main subcompartments: The cortex and the medulla. Each subcompartment contains numerous subtypes of thymic epithelial cells (TECs), in addition to dendritic cells, mesenchymal cells and endothelial cells (1-3). In addition, the thymus establishes and maintains thymic microenvironments, which are capable of supporting the efficient development of T cells. The maintenance of these microenvironments is dependent upon the specialized functions of thymic stromal cells, and other major components of the thymic microenvironment $(4,5)$. During the development and maturation of thymocytes from bone marrow-derived $\mathrm{T}$ cell progenitors, three main events serve a critical role in each $\mathrm{T}$ cell bearing a unique $\mathrm{T}$ cell receptor (TCR): The rearrangement and expression of TCR $\alpha$ and $\beta$ loci, which depends on their somatic assembly; positive selection [the identification of cells that are able to recognize self-major histocompatibility complex (MHC) in antigen presentation to $\mathrm{T}$ cells]; and negative selection (the elimination of $\mathrm{T}$ cells that are potentially autoreactive). T cells that survive the selection processes eventually become mature cluster of differentiation (CD) $4^{+}$or $\mathrm{CD}^{+}$ single positive T cells (Fig. 1). These processes ensure a population of non-autoreactive peripheral T cells. T cell migration is directed by several mediators, including chemokine receptors and $\mathrm{G}$ protein-coupled receptors (GPCR), which are supported by guiding stromal structures and by TECs, including cortical TECs and medullary TECs (mTEC). The TECs form a three-dimensionally oriented network, rather than the more 'typical' two-dimensional (2D) epithelial structures $(6,7)$. It is important to determine the molecular mechanisms underlying the thymic regulation of $\mathrm{T}$ cell development and of the proteins involved in $\mathrm{T}$ cell recognition. However, to the best of our 
knowledge, the mechanisms underlying these processes have not yet been fully explored.

\section{Molecular mechanisms underlying regulatory $T$ cell generation in the thymus}

In 1969, Nishizuka and Sakakura were the first to present a mechanism for the generation of regulatory $\mathrm{T}\left(\mathrm{T}_{\mathrm{reg}}\right)$ cells in the thymus, based on a neonatal thymectomy experiment (8). $\mathrm{T}_{\text {reg }}$ cells in the thymus are vital for the negative regulation of immune-mediated inflammation, which features prominently in autoimmune and autoinflammatory disorders, acute allergies, cancer, chronic infections and commensal microbiota. They are also important for the regulation of metabolic inflammation for homeostasis and peripheral tolerance (9-11). Recent studies have demonstrated that mice lacking the forkhead box P3 (Foxp3) transcription factor experience overwhelming autoimmune pathology, which they succumb to in a matter of weeks $(12,13)$. Although CD25 is not a specific marker expressed exclusively on $\mathrm{T}_{\mathrm{reg}}$ cells, using specific anti-CD25 antibodies for the depletion or inactivation of $\mathrm{T}_{\text {reg }}$ cells, in combination with immunostimulation, is an attractive treatment modality, particularly in anti-tumour immunotherapy (14). The current understanding is that $\mathrm{T}_{\mathrm{reg}}$ cell development occurs when the TCR avidity for self-antigens lies between the TCR avidities that drive positive and negative selection (15-19). TCR engagement is also known to stimulate various downstream signaling molecules and transcription factors. This stimulation leads to an intricate web of downstream intracellular signaling events. Proteins important in thymic $\mathrm{T}_{\text {reg }}$ cell function include phosphoinositide 3-kinase, protein kinase B (AKT), mammalian target of rapamycin (mTOR), nuclear factor of activated $\mathrm{T}$ cells, transcription factor activator protein 1 and nuclear factor- $\mathrm{\kappa B}$ (NF-kB). Numerous pathways contribute to $T_{\text {reg }}$ cell development, including the TCR, AKT-mTOR and NF- $\kappa$ B pathways, among others (20-22). Various types of antigen-presenting cells (APCs) capture and present antigens to thymocytes through a complex network of signaling pathways (Fig. 2). In addition, calcium signaling appears to be involved in thymic $\mathrm{T}_{\text {reg }}$ cell development (23). Furthermore, increased generation of the Foxp3 protein in developing thymic $\mathrm{T}_{\text {reg }}$ cells may have a positive role in $\mathrm{Ca}^{2+}$ signaling $(24,25)$. However, calcium is also a powerful negative regulator of Foxp3 in the AKT-mTOR pathway. Phosphatidylinositol-4,5-bisphosphate 3-kinase/AKT signaling regulates the phosphorylation and inhibition of forkhead box $\mathrm{O}$ (FoxO) transcription factors. The FoxO transcription factors have recently been reported to facilitate the expression of Foxp3 and $\mathrm{T}_{\text {reg }}$ cell development (26-28). Although natural $\mathrm{T}_{\text {reg }}\left(\mathrm{nT}_{\text {reg }}\right)$ and induced $\mathrm{T}_{\text {reg }}$ $\left(\mathrm{iT}_{\text {reg }}\right.$ ) cells can enforce tolerance, $\mathrm{iT}_{\text {reg }}$ cells, such as those derived from commensal bacteria in the gut, may have a particularly important role as they increase antigen receptor diversity $(29,30)$. The mechanisms underlying the development and antigen specificities of $\mathrm{nT}_{\text {reg }}$ and $\mathrm{iT}_{\text {reg }}$ cells are likely to differ.

Over the past few years, substantial progress has been made in understanding the developmental process of thymic $\mathrm{T}_{\text {reg }}$ cells and the molecular mechanism underlying their regulation in the thymus. However, there remain numerous unanswered questions. For example, the molecular differences

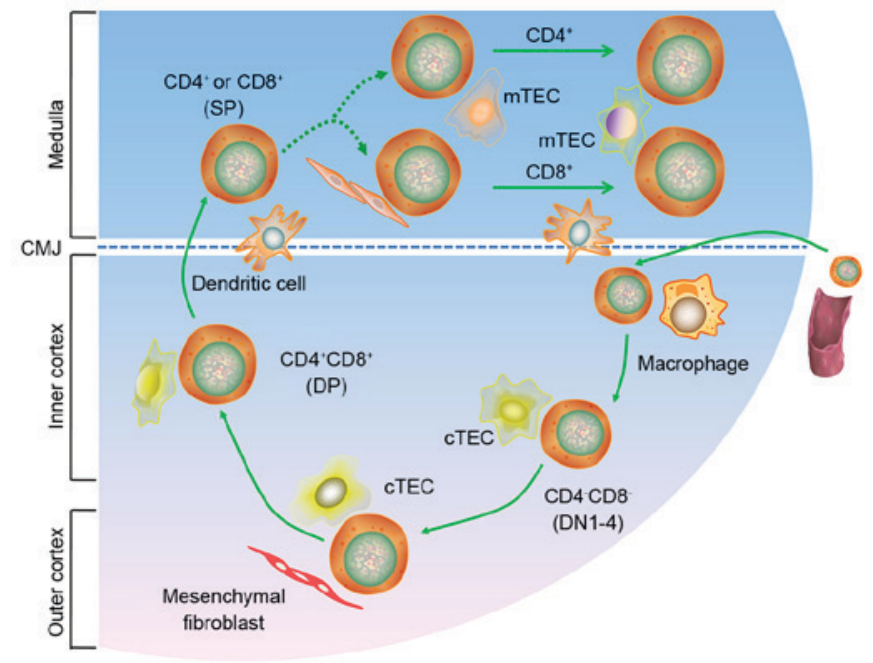

Figure 1. T cell development in the thymus. CD, cluster of differentiation; CMJ, corticomedullary junction; cTEC, cortical thymic epithelial cell; DN, differentiation; DP, double positive; mTEC, medullary thymic epithelial cell; SP, single positive.

between immature $\mathrm{CD}^{+}{ }^{+}$single positive (SP) thymocytes in the thymus and naive peripheral $T$ cells remain unknown. In addition, it remains to be elucidated why Foxp3 expression occurs predominantly in $\mathrm{CD}^{+}$, and not $\mathrm{CD} 8^{+}$, $\mathrm{SP}$ thymocytes, The present review aimed to understand these molecular mechanisms and how these molecular components are 'wired' into regulatory signaling and transcriptional networks. Achieving this may aid in the improvement of therapeutic strategies used to treat autoimmune and inflammatory disorders.

\section{Effects of cytokines on thymic function}

Cytokines serve as molecular messengers between immune cells, and have been reported to be of major importance to thymic function. The effects of cytokine cascades on thymic function are generally well understood. Almost all types of thymic cells can produce cytokines, either spontaneously or following stimulation with stimulating agents, including lipopolysaccharides, phytohemagglutinin and ionomycin. The most important of the thymic cell subsets are TECs, which are the principal source of cytokines and chemokines required in early $\mathrm{T}$ cell development (31). The differential expression of major cytokines produced by TECs can be divided into four branches: Hemopoietins, proinflammatory cytokines, suppressor cytokines and interleukin (IL)-6 and IL-7 cytokines $(32,33)$. Notably, cytokines and other growth factors serve important roles in thymic function, regulating various cellular processes. However, the functions of numerous cytokines in the thymus are not well understood. Understanding the effects of intrathymic cytokines may reveal some unknown aspects of thymic physiology.

The thymus produces hormones and cytokines that regulate immune function. A previous study identified at least six types of thymic cells (34). The histological features of the thymus are broadly divided into the central medulla and a peripheral cortex. Previous research has demonstrated that cytokine secretion by $\mathrm{T}$ lymphocytes has a vital role in 


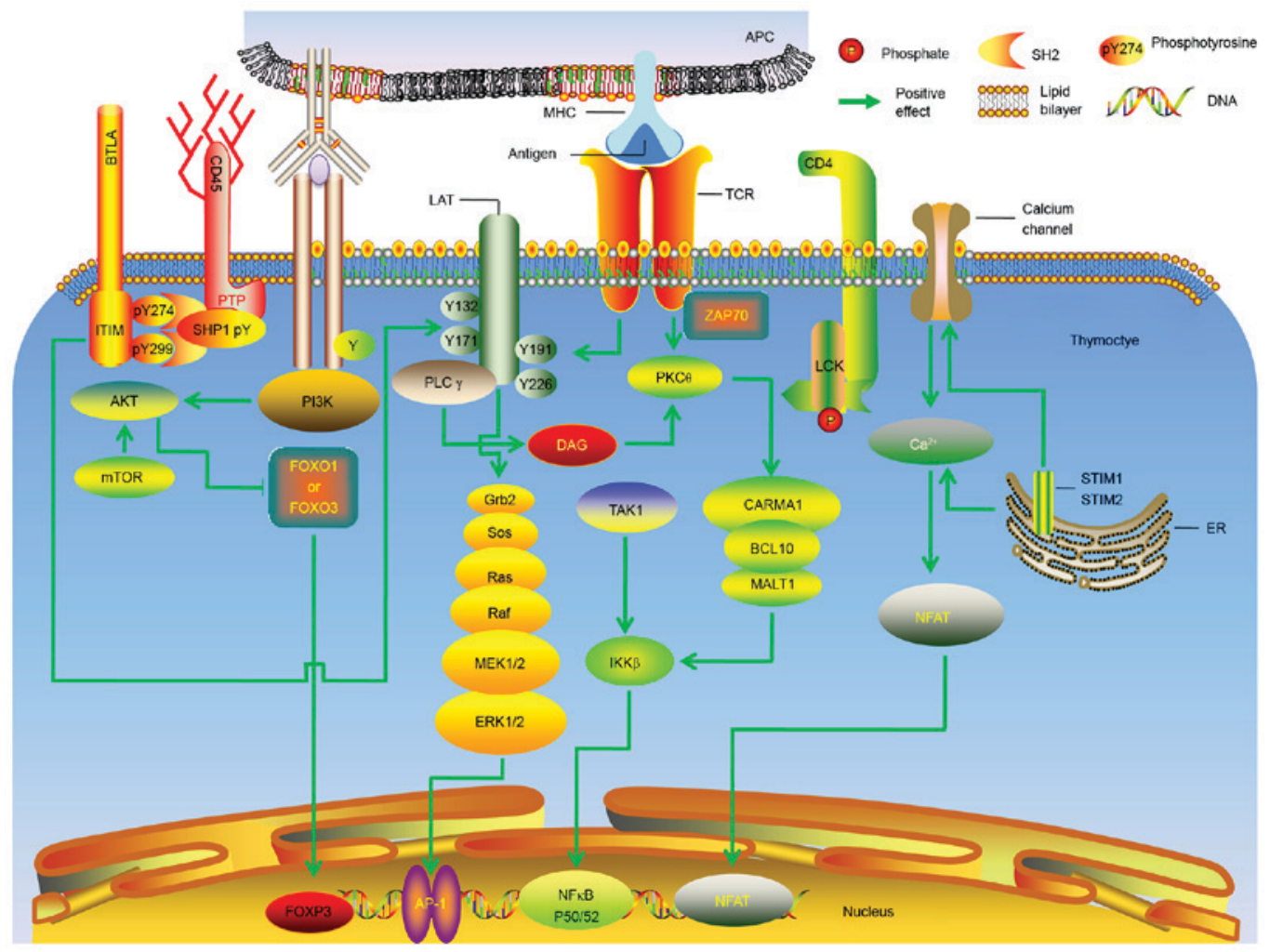

Figure 2. Molecular mechanisms underlying the generation of thymic regulatory T cells. Molecular signals downstream of the TCR are presented. AP, activator protein; APC, antigen-presenting cell; BCL, B cell lymphoma; BTLA, B and T lymphocyte attenuator; Ca, calcium; CARMA, CARD-containing MAGUK protein; CD, cluster of differentiation; DAG, diacylglycerol; ER, endoplasmic reticulum; ERK, extracellular signal-regulated kinase; IKK $\beta$, inhibitor of nuclear factor $\mathrm{\kappa B}$; ITIM, immunoreceptor tyrosine-based inhibition motif; MEK, mitogen-activated extracellular signal-regulated kinase; MHC, major histocompatibility complex; FoxO, forkhead box protein O; FOXP3, forkhead box protein 3; NFAT, nuclear factor of activated T; Grb, growth factor receptor-bound protein; LAT, linker for activation of T cells; LCK, lymphocyte-specific protein tyrosine kinase p56; MALT, mucosa-associated lymphoid tissue lymphoma translocation protein; mTOR, mechanistic target of rapamycin; NF, nuclear factor; PI3K, phosphatidylinositol-4,5-bisphosphate 3-kinase; PK, protein kinase; PL, phospholipase; PTP, protein-tyrosine phosphatase; Ras, rat sarcoma also known as p21; Raf, rapidly accelerated fibrosarcoma; SHP, SH2-containing protein tyrosine phosphatase; SOS, Son of Sevenless; STIM, stromal interaction molecule; TAK, transforming growth factor beta-activated kinase; ZAP70, $\zeta$-associated protein of $70 \mathrm{kD}$.

mounting adaptive immune responses (35). In addition, the large number of cytokines produced by the thymus maintains a fine balance between thymocyte proliferation, maturation, activation, differentiation and survival inhibition. Thymic cells also secrete the peptides IL-1, IL-3, IL-4 and IL-6, and three major thymic hormones, thymosins, thymopoietin and thymulin (36-39). Thymic hormones serve a major role in preserving the functions of the immune system, and cytokines have essential roles in the control of immune responses.

Cytokines are small polypeptides that regulate cell function and are predominantly secreted by immune cells. Numerous cytokines responsible for the modulation of $\mathrm{T}$ cell differentiation are produced by thymocytes and TECs. The ability of thymocytes to produce cytokines is important in the regulation of thymic cytokine production and the responses to their action (Fig. 3). Of these regulators, IL-7 serves a particular role in thymocyte differentiation; IL-7 has been reported to promote the rearrangement of TCR genes by enhancing the production and activity of recombinases $(40,41)$. The thymic production of $\mathrm{T}_{\text {reg }}$ cells requires IL-2, which is also required during $\mathrm{T}$ cell development in the thymus and for the maturation of $\mathrm{T}_{\text {reg }}$ cells. Recent studies have reported that IL-2 receptor is functionally active within the thymus; it increases the number of $\mathrm{CD}^{+}{ }^{+} \mathrm{Foxp}^{+}$thymocytes and the expression of Foxp3 and

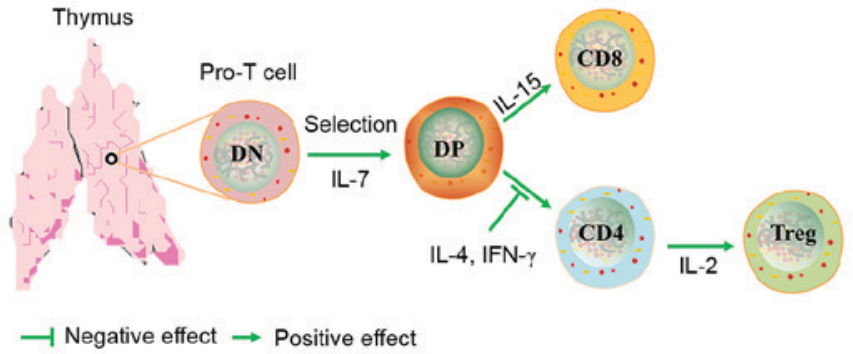

Figure 3. Role of cytokines in T cell development. CD, cluster of differentiation; DN, double negative; DP, double positive; IL, interleukin; Treg, regulatory $\mathrm{T}$ cell.

CD25 to normal levels (42-44). IL-4 is another cytokine produced by $\mathrm{T}$ cells whose receptor contains a $\gamma(\mathrm{c})$-chain. It has previously been demonstrated that IL-4 is synergistic with IL-2 in the induction of thymocyte proliferation in fetal thymic organ culture. In addition, IL-4 supports thymocytes through successive phases of proliferation, acting alongside stimulatory agents $(45,46)$. Recently, research has been directed at the cytokine IL-10, which is produced by $\mathrm{T}_{\text {reg }}$ cells, and other chronically stimulated Thelper cells, B cells and APCs. IL-10 is important for maintaining immune homeostasis at mucosal surfaces and also contributes to immune suppression (47-49). 


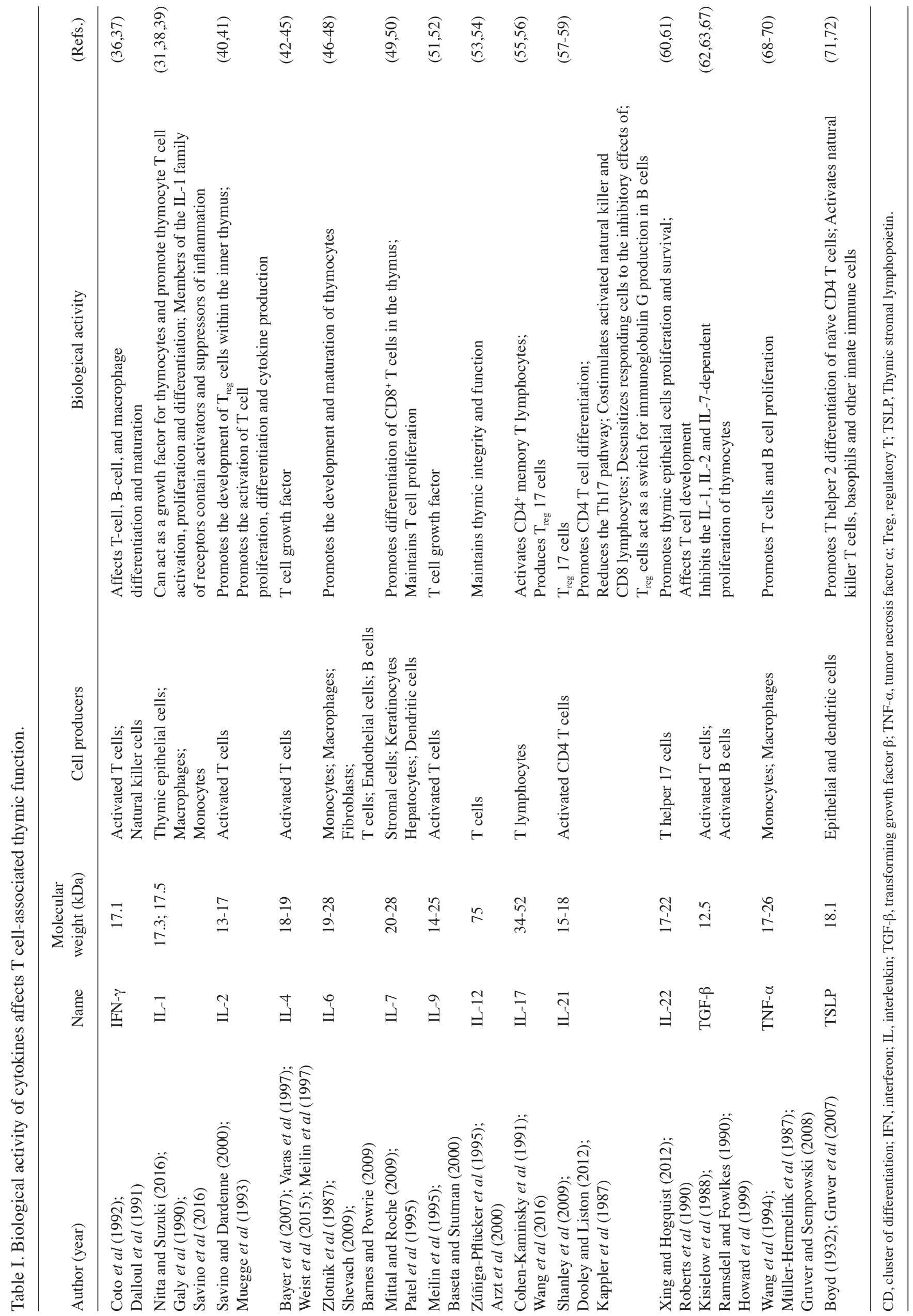




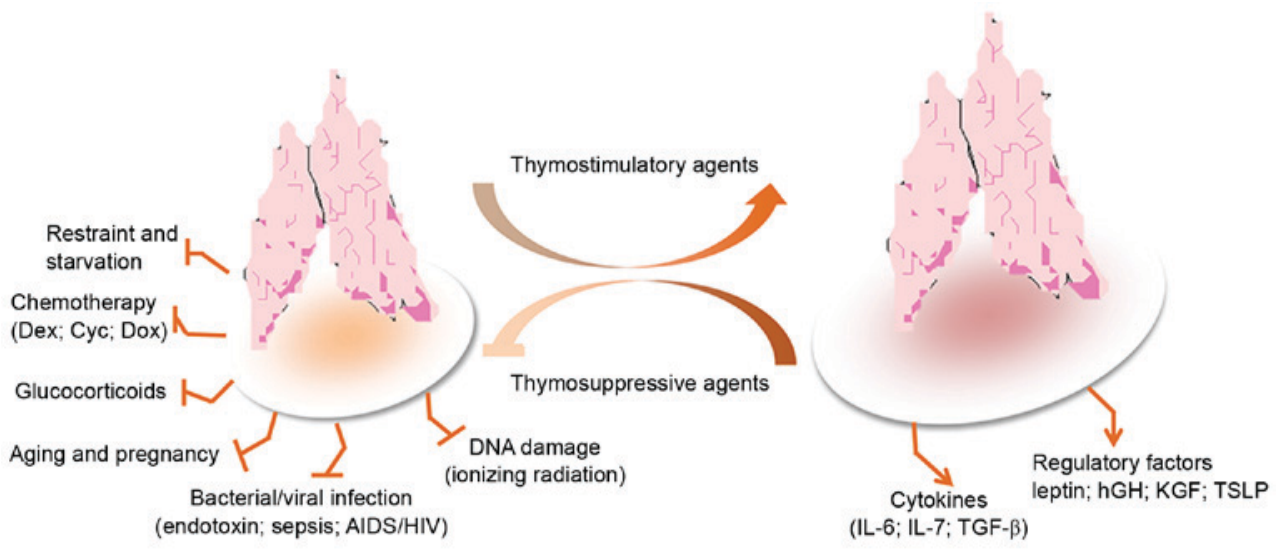

$\longrightarrow$ Negative effect $\rightarrow$ Positive effect

Figure 4. Model of stress-induced thymic atrophy, and thymosuppressive and thymostimulatory mediators. AIDS, acquired immunodeficiency syndrome; Cyc, cyclophosphamide; Dex, dexamethasone; Dox, doxorubicin; HIV, human immunodeficiency virus; hGH, human growth hormone; IL, interleukin; KGF, keratinocyte growth factor; TGF- $\beta$, transforming growth factor- $\beta$; TSLP, thymic stromal lymphopoietin.

Interferon (IFN)- $\gamma$ has numerous effects on TECs; it activates TECs and increases surface expression of MHC classes I and II, and other membrane proteins (50). Furthermore, IFN- $\gamma$ stimulates the secretion of IL- 6 by TECs (51). IFN- $\gamma$ also supports thymocyte differentiation, through its action on TEC functions. Tumor necrosis factor (TNF)- $\alpha$ has been reported to have an important role in the regulation of thymocyte production, inducing apoptosis and the proliferation of immature CD3-CD4-CD8- T cells in the presence of IL-7 (52). Furthermore, TNF- $\alpha$ and IL-1 participate as cofactors in the induction of CD4-CD8- thymocyte commitment and differentiation (53). TNF- $\alpha$ also stimulates the production of IL-6 and enhances the apoptosis of $\mathrm{CD} 4{ }^{+} \mathrm{CD}^{+}$cells induced by glucocorticoids $(54,55)$.

Some molecules are multifunctional and serve different functions in the cytokine system within the thymus than they do in peripheral compartments of the immune system. For example, some cytokines are pleiotropic in their biological activities and exhibit different roles in these different systems. The principal roles of thymic cytokines are in constitutive processes, including thymocyte migration and development, and the mediation of cell populations, but not inducible ones, such as immune response/tolerance or inflammation, as in the periphery. The synthesis of cytokines and the expression of their receptors in the thymus is usually spontaneous, or is induced by cell-cell interactions, unlike in the periphery. Information regarding the production of cytokines in the thymus and the biological activity of these cytokines is summarized in Table I.

\section{Regulation of molecular mechanisms in stress-mediated thymic atrophy and involution}

Stress is able to disrupt homeostasis of the immune system, and various stressful conditions cause acute thymic involution, including emotional distress, malnutrition and pregnancy $(56,57)$. Furthermore, numerous processes can trigger thymic involution during pathological conditions, such as bacterial and viral infections, inflammation, disease, clinical cancer treatment and preparative regimens for bone marrow transplants (58), as presented in Fig. 4. Therefore, mechanisms must exist to regulate these processes in various contexts. It is well known that the thymus serves an important role in the body's immune response. It provides the microenvironment essential for the development of $\mathrm{T}$ cells from hematopoietic stem cells. The central functions of the thymus are critical to immune tolerance in several rodent and large animal models under normal or pathological conditions. These functions act through various mechanisms, such as clonal deletion or clonal anergy of self-reactive $\mathrm{T}$ cells, elimination or control of self-reactive T cells, and anergy of self-reactive T cells (59-63). Recent mechanistic studies regarding central and peripheral $\mathrm{T}$ cell tolerance have assisted in the design of novel, immunomodulating therapeutic strategies for the treatment of autoimmune diseases, and improve the prevention, detection and treatment of cancer and associated diseases, as well as exert immunoregulatory effects in transplantation outcomes using pharmacological or biological interventions (64-66). Immunosenescence and immune atrophy, which are associated with reduced immunity, are complex processes that have yet to be fully understood. Numerous factors exert a negative effect on thymopoiesis, acute stress-induced thymic atrophy and on chronic thymic involution associated with aging. These factors include starvation, environmental stressors, bacterial infection, and irradiation or immunosuppressive therapies (67-70).

The shrinkage of the thymus was reported $>80$ years ago by Boyd (71); however, the underlying mechanisms are not well understood. Immunosenescence is defined as deterioration in the immune system, which is associated with aging (72-74), and has attracted increasing interest in the scientific and health-care sectors alike. Thymic atrophy has often been observed due to the direct or indirect influences of drugs or the environment on the thymus. However, one other major consideration in thymic atrophy is a systemic rise in glucocorticoids and inflammatory cytokines. Unfortunately, the thymus is acutely sensitive to various stresses and injuries; therefore, it is often considered as a 'barometer of stress' for the body. Prolonged thymic atrophy in stress situations can contribute to peripheral $\mathrm{T}$ cell deficiency or can 
inhibit immune reconstitution, thus resulting in a decrease in thymopoiesis $(75,76)$. Therefore, mechanistic studies have increasingly focused on thymic atrophy. A commonly used mouse model of endotoxemia-induced acute thymic atrophy has been used to reveal the effects of acute stress on thymopoiesis. For example, in a lipopolysaccharide (LPS)-induced acute thymic atrophy model, microarray analysis revealed $>11,000$ probe sets with significant alterations ( $>1.4$-fold), 1 day after an LPS challenge. This finding has important implications regarding how the direct intrathymic response to an endotoxin challenge contributes to thymic involution during endotoxemia (77). In endotoxin-stressed mice, it has previously been reported that leptin administration augments thymopoiesis in LPS-treated leptin-deficient $(o b / o b)$ mice, but not in normal mice (78). Furthermore, a recent study indicated that the number of thymocytes and TECs was significantly decreased in LPS-treated neonatal thymic involution (79).

Age-associated thymic involution must also be considered. Aging is accompanied by a decline in the function and development of the immune system. Understanding the aging process, and how that process can be delayed or reversed, may allow us to take action to adopt healthier lifestyles and live longer. Age-associated thymic involution is characterized by progressive diminution of novel $\mathrm{T}$ cell production (80). However, many previous findings are contradictory. Some studies have reported the effects of aging on the function of neutrophils, macrophages and natural killer cells, whereas other studies have reported no association $(81,82)$. In addition, some studies have demonstrated that the systemic administration of keratinocyte growth factor (KGF) enhances $\mathrm{T}$ cell lymphopoiesis by stimulating TECs to secrete various cytokines that then act on developing thymocytes in young and old mice $(83,84)$. Furthermore, a previous study was conducted on $\mathrm{C} 57 \mathrm{BL} / 6 \mathrm{xDBA} / 2$ recombinant inbred strains of mice to identify the genetic loci influencing age-associared thymic involution, and demonstrated that the strongest quantitative trait loci influencing the rate of thymic involution in the recombinant-inbred mice were mapped to chromosome (Chr) 9 (D9Mit20 at $62 \mathrm{cM}$ ) and Chr 10 (D10Mit61 at $32 \mathrm{cM}$ ) (85).

It is well known that stress on the immune system leads to the suppression of immune cell functions, such as in T cells, macrophages, dendritic cells and B cells, and the atrophy of immune organs, predominantly the thymus and spleen. The thymus is one of the central organs of the immune system, and is essential for the development of the adaptive immune system. Insult, infection, dysregulation of positive and negative selection, suppression of cell adhesion, chemotaxis, cytotoxicity, increased apoptosis or antigen presentation in the thymus, may all lead to autoimmunity or immunosuppression (86,87). Previous studies have suggested that exposure to immunosuppressive agents, such as diethylstilbestrol, dexamethasone (DEX), azathioprine, cyclophosphamide (Cyc), 2,3,7,8-tetrachlorodibenzo- $p$-dioxin or cyclosporin A may induce immunotoxic effects resulting in hypocellularity, apoptosis and atrophy in the thymus (88-92). This provides evidence regarding the molecular mechanisms and cellular targets involved in thymic atrophy-induced immunosuppression. DEX is a synthetic glucocorticoid compound with potent anti-inflammatory activity, which is associated with clinically significant side effects that severely limit its therapeutic use.
In a previous study, DEX (20 mg/ $\mathrm{kg})$ was administered to $\mathrm{C} 57 \mathrm{Bl} / 6$ mice via intraperitoneal injection; the thymuses were then harvested 5 days after treatment. Analysis of the thymic tissues detected a depletion of $\mathrm{CD} 4{ }^{+} \mathrm{CD} 8^{+}$double positive thymocytes, and upregulation of IL-22 and IL-23 in wild-type mice (93). In another study, the immunosuppressant cyclosporin A was reported to induce extensive reductions in the autoimmune regulator tolerance-inducing $\mathrm{MHC}$ class II ${ }^{\text {high }}$ mTECs (mTEC ${ }^{\text {high }}$ ). The most distinctive effects of Cyc and DEX exposure were extensive reductions in thymocytes and stromal cells, and, as with cyclosporin A, severely depleted tolerance-inducing mTEC $^{\text {high }}(91)$.

\section{Prediction of potential drug targets on the thymus using proteomics}

The thymus remains still largely uncharted territory that invites further investigation. Understanding the role of the thymus in $\mathrm{T}$ cell generation and homeostasis, and understanding exactly how such systems work and what proteins are involved has resulted in greater interest in thymus organogenesis. The application of systems biology, combined with more traditional methods, is essential to uncover and optimize the molecular mechanisms underlying effects (drug-induced or otherwise) on the thymus. These methods will allow the study of novel aspects of thymic function and aid understanding regarding thymic function, morphogenesis and development. This knowledge may then be used to identify potential drug targets. In addition, these methods will prove useful not only for studying gene and protein function in thymus organogenesis, but also for clarifying the origin and lineage relationship between cortical and medullary epithelial cell types. Recently, modern approaches to chemical genomics, metabolomics, genomics, transcriptomics, pharmacogenomics, microbiomics and proteomics have proved to be useful in the identification and characterization of molecular mechanisms underlying all aspects of pharmacological sciences and physiological processes, and in other areas $(94,95)$. Therefore, evidence suggests that proteomics may be effectively used in the in-depth study of the thymus in different models and pathological conditions.

Proteomics is the large-scale study of proteins, and facilitates the systematic analysis of protein molecules in complicated biological systems. Turiák et al (96) focused on the proteomic characterization of thymocyte-derived microvesicles (MVs) and apoptotic bodies in BALB/c mice; 195 and 142 proteins were identified in MVs and apoptotic bodies, respectively. This previous study also identified numerous molecules known to serve important roles in the immune system, such as MHCI, MHCII, CD5 and CD97 in MVs, and CD45 in both types of vesicles. Similarly, Billing et al (97) used proteomic profiling analysis to measure the non-genomic and concomitant genomic effects of acute restraint stress on rat thymocytes. In recent years, several methods have been developed for relative and absolute quantitative proteomics. The most widely used quantitative techniques include gel-based [2D gel electrophoresis, difference gel electrophoresis (DIGE)] and liquid chromatography-mass spectrometry (MS)-based methods (isotope-coded affinity tag, stable isotope labeling with amino acids in cell culture, 
isobaric tags for relative and absolute quantitation). MS-based proteomics methods are typically divided into two categories: Label-free or label-based approaches (98). Proteomics research is applied to a wide range of biological systems for the study of differentially expressed proteins, particularly candidates for biomarker discovery and validation, understanding disease processes and clinical proteomics (99). Notably, in a previous study quantitative 2D-DIGE with matrix-assisted laser desorption/ionization-time of flight (TOF)/TOF MS was used to identify 108 proteins with differential subcellular localizations in rat thymocytes; this may be the first study to determine the rapid effects of stress-induced hypothalamus-pituitary-adrenal activation at the proteome level in vivo (97). According to our current understanding, doxorubicin (DOX) treatment leads to degeneration of the thymus. Proteomics analysis is consistent with the notion that DOX treatment in vivo leads to thymic senescence (100). Cyc has also been reported to induce immunosuppression and thymic atrophy. Proteomic analysis indicated that possible target-related processing was instigated following Cyc-treatment in mice (101). Apoptosis serves an essential role in the development and maturation of T lymphocytes during mammalian thymus maturation. Experiments have indicated that several proteins were differentially regulated in the cytosol of T cell precursors by a signal from TCR, as identified using proteomic techniques (102). Proteomics has been widely used to study the experimentally induced acute phase reaction, and to study numerous disease models associated with cancer and inflammatory diseases $(103,104)$. A previous study revealed the cellular and molecular mechanisms using proteomic approaches combined with bioinformatics analysis (105). Despite the increased use of proteomics, knowledge of protein interactions and pathway networks remains largely incomplete; however, data generated by quantitative proteomics can still provide valuable insights (106).

\section{Final remarks}

More than 50 years ago, Miller (107) conducted seminal studies on the immunological function of the thymus using neonatally thymectomized mice. The importance of this primary lymphoid organ was quickly established, as the thymus provides a unique microenvironment in which $\mathrm{T}$ cells or $\mathrm{T}$ lymphocytes undergo development, differentiation and clonal expansion during the physiological development of the immune system. In recent years, there has been a marked interest in the association between the immune system and the thymus, generating results that confirmed that the thymus was endowed with an immune function. The immune system has evolved to mount an effective defense against pathogens and to minimize deleterious immune-mediated inflammation caused by commensal microorganisms, immune responses against self and environmental antigens, and metabolic inflammatory disorders. It appears that $\mathrm{T}_{\text {reg }}$ cell-mediated suppression serves as a vital mechanism in the negative regulation of immune-mediated inflammation, and features prominently in autoimmune and autoinflammatory disorders, and pathologies induced by fungi, parasites, allergies, acute and chronic infections, cancer and metabolic inflammation. $\mathrm{T}_{\text {reg }}$ cells are considered important to researchers in their efforts to increase the efficacy of vaccines for cancer, acquired immune deficiency syndrome and autoimmune diseases. The discovery that Foxp3 is the transcription factor that specifies the $\mathrm{T}_{\text {reg }}$ cell lineage has facilitated recent progress in understanding the biology of $\mathrm{T}_{\text {reg }}$ cells. These findings may provide novel targets for subsequent drug development.

There is an increasingly in-depth understanding of cytokines and their activities in biological pathways. Therefore, an improved understanding regarding the cytokine network is essential to determine the role of numerous key cytokines, and to modulate thymic function. Cytokines, such as ILs, may be useful in improving the functionality of the thymus and may be used to treat immunodeficiency or autoimmune diseases. It has been reported that cytokines, including IL-6, IL-7 receptor, IL-10 and IL-22, serve a key regulatory role in T cell growth and differentiation processes in the thymus. These cytokines may be mediated through various regulatory mechanisms and signaling pathways to establish a protective effect on the thymus. Understanding these pathways will increase the understanding of the regulatory mechanism of the thymus and the biology of $\mathrm{T}_{\text {reg }}$ cells and secreted cytokine function. Previous studies have analyzed the effects of cytokine therapy as a complementary schedule to conventional therapy with $\gamma$-globulin (108-110). The results suggested that the treatment has a long-term positive effect on the immune response, relative to other therapeutic interventions. A combination of IFN- $\alpha 2 b$, thymic factors, $\gamma$-globulin and granulocyte-macrophage colony-stimulating factor may be a promising to treat common variable immunodeficiency. In addition, a previous study reported that cytokines not only serve an essential role during early $\mathrm{T}$ cell development, but are also responsible for the development of other thymic cells, such as thymic dendritic cells, generated from precursors produced in bone marrow (32). At present, information on this topic is limited. An essential difference between cytokine production inside the thymus and in peripheral organs is the different levels of dependence on cell activation, and possibly cross talk, depending on the cytokine environment and situation.

Studying protective mechanisms may provide novel directions in research and the development of drugs for the treatment of various stresses to the thymus, including immunosenescence, immune atrophy and immunosuppression. There have been reports of several small molecules having a protective effect on the thymus, including leptin, KGF and IL-22. Studies have also explored the molecular mechanisms involved, predominantly using mice $(70,111)$. In various chemical stress and thymic atrophy models, these active molecules can enhance the remodeling of the thymus, protecting the thymus from some stressors, such as those involved in aging, as well as hunger, radiation, hormones and immunosuppressants. Notably, researchers have made great progress in examining the numerous mechanisms that contribute to immune suppression and have provided a future direction for research and a novel manner of developing immune-modulating drugs (112). It must be noted that there are differences between immunosenescence, immune atrophy and immunosuppression; therefore, these situations should be treated differently when developing specific molecular signaling pathways and in targeted drug development. The development of novel drugs, and signal transduction research concerning these mechanisms, may benefit patients that are immunocompromised, in a pathological state, 
or a combination, to reduce the side effects of other drugs on the thymus.

During the last decade, the development of proteomics technology and protein targets for drug generation and drug screening mechanisms has provided novel tools for biomedical research $(113,114)$. There have been several reports regarding thymic molecular mechanisms using proteomics technology; therefore, a more comprehensive analysis of protein alterations in the thymus under various circumstances has been established. This, combined with the related molecule-function databases, including UniProt, the Kyoto Encyclopedia for Genes and Genomes and the Gene Ontology database, has enabled protein network data analysis to screen for known or predicted drug-protein or protein-protein interactions in the thymus. A greater understanding of the mutual regulation of protein molecules may allow the prediction of possible molecular drug targets and drug development pathways. Existing proteomics studies have provided some pathways for protein regulation of signal transduction. These pathways are intricate webs of downstream intracellular signaling events that ultimately result in specific thymic immune response stresses. This understanding may provide novel ways of treating immunological diseases by targeting the stress protein molecules in the thymus, and may be useful in improving the functionality of the thymus. Collectively, these studies suggest that the markedly complex action mechanisms underlying immunomodulatory effects in the thymus are a promising therapeutic target for treatment of the immune system.

\section{Acknowledgements}

This review was supported by the Young Scientists Fund of the National Natural Science Foundation of China (grant no. 81403395), the Traditional Chinese Medicine Bureau of Guangdong Province [grant no. (2014) 539] and the Specific Research Fund for TCM Science and Technology of Guangdong Provincial Hospital of Chinese Medicine (grant nos. YN2015QN09, YN2016QJ11 and YN2015QN12).

\section{References}

1. Gordon J and Manley NR: Mechanisms of thymus organogenesis and morphogenesis. Development 138: 3865-3878, 2011.

2. Blackburn CC and Manley NR: Developing a new paradigm for thymus organogenesis. Nat Rev Immunol 4: 278-289, 2004.

3. Skogberg G, Lundberg V, Berglund M, Gudmundsdottir J, Telemo E, Lindgren S and Ekwall O: Human thymic epithelial primary cells produce exosomes carrying tissue-restricted antigens. Immunol Cell Biol 93: 727-734, 2015.

4. Anderson G and Jenkinson EJ: Lymphostromal interactions in thymic development and function. Nat Rev Immunol 1: 31-40, 2001.

5. Su M, Hu R, Jin J, Yan Y, Song Y, Sullivan R and Lai L: Efficient in vitro generation of functional thymic epithelial progenitors from human embryonic stem cells. Sci Rep 5: 9882, 2015.

6. Fan Y, Tajima A, Goh SK, Geng X, Gualtierotti G, Grupillo M, Coppola A, Bertera S, Rudert WA, Banerjee I, et al: Bioengineering thymus organoids to restore thymic function and induce donor-specific immune tolerance to allografts. Mol Ther 23: 1262-1277, 2015.

7. van Ewijk W, Wang B, Hollander G, Kawamoto H, Spanopoulou E, Itoi M, Amagai T, Jiang YF, Germeraad WT, Chen WF and Katsura Y: Thymic microenvironments, 3-D versus 2-D? Semin Immunol 11: 57-64, 1999.

8. Nishizuka Y and Sakakura T: Thymus and reproduction: Sex-linked dysgenesia of the gonad after neonatal thymectomy in mice. Science 166: 753-755, 1969.
9. Josefowicz SZ, Lu LF and Rudensky AY: Regulatory T cells: Mechanisms of differentiation and function. Annu Rev Immunol 30: 531-564, 2012.

10. Hsieh CS, Lee HM and Lio CW: Selection of regulatory T cells in the thymus. Nat Rev Immunol 12: 157-167, 2012.

11. Wang YM, Ghali J, Zhang GY, Hu M, Wang Y, Sawyer A, Zhou JJ, Hapudeniya DA, Wang Y, Cao Q, et al: Development and function of Foxp3(+) regulatory T cells. Nephrology (Carlton) 21: 81-85, 2016

12. Lahl K, Loddenkemper C, Drouin C, Freyer J, Arnason J, Eberl G, Hamann A, Wagner H, Huehn J and Sparwasser T: Selective depletion of Foxp3 ${ }^{+}$regulatory $\mathrm{T}$ cells induces a scurfy-like disease. J Exp Med 204: 57-63, 2007.

13. Kim JM, Rasmussen JP and Rudensky AY: Regulatory T cells prevent catastrophic autoimmunity throughout the lifespan of mice. Nat Immunol 8: 191-197, 2007.

14. Rosalia RA, Štěpánek I, Polláková V, Šímová J, Bieblová J, Indrová M, Moravcová S, Přibylová H, Bontkes HJ, Bubeník J, et al: Administration of anti-CD25 mAb leads to impaired $\alpha$-galactosylceramide-mediated induction of IFN- $\gamma$ production in a murine model. Immunobiology 218: 851-859, 2013.

15. Wong J, Obst R, Correia-Neves M, Losyev G, Mathis D and Benoist C: Adaptation of TCR repertoires to self-peptides in regulatory and nonregulatory $\mathrm{CD}^{+}{ }^{+} \mathrm{T}$ cells. J Immunol 178: 7032-7041, 2007.

16. Pacholczyk R, Ignatowicz H, Kraj P and Ignatowicz L: Origin and $\mathrm{T}$ cell receptor diversity of Foxp $3{ }^{+} \mathrm{CD} 4{ }^{+} \mathrm{CD} 25^{+} \mathrm{T}$ cells. Immunity 25: 249-259, 2006.

17. Hsieh CS, Liang Y, Tyznik AJ, Self SG, Liggitt D and Rudensky AY: Recognition of the peripheral self by naturally arising $\mathrm{CD} 25^{+} \mathrm{CD} 4^{+} \mathrm{T}$ cell receptors. Immunity 21: 267-277, 2004.

18. Maloy KJ and Powrie F: Regulatory T cells in the control of immune pathology. Nat Immunol 2: 816-822, 2001.

19. Klein L, Kyewski B, Allen PM and Hogquist KA: Positive and negative selection of the T cell repertoire: What thymocytes see (and don't see). Nat Rev Immunol 14: 377-391, 2014.

20. Chapman NM and Chi H: mTOR links environmental signals to T cell fate decisions. Front Immunol 5: 686, 2015.

21. Akimzhanov AM and Boehning D: IP3R function in cells of the immune system. WIREs Membr Transp Signal 1: 329-339, 2012.

22. Sauer S, Bruno L, Hertweck A, Finlay D, Leleu M, Spivakov M, Knight ZA, Cobb BS, Cantrell D, O'Connor E, et al: T cell receptor signaling controls Foxp3 expression via PI3K, Akt, and mTOR. Proc Natl Acad Sci USA 105: 7797-7802, 2008.

23. Schwarz A, Schumacher M, Pfaff D, Schumacher K, Jarius S, Balint B, Wiendl H, Haas J and Wildemann B: Fine-tuning of regulatory $\mathrm{T}$ cell function: The role of calcium signals and naive regulatory $\mathrm{T}$ cells for regulatory $\mathrm{T}$ cell deficiency in multiple sclerosis. J Immunol 190: 4965-4970, 2013.

24. Lin J, Yang L, Silva HM, Trzeciak A, Choi Y, Schwab SR, Dustin ML and Lafaille JJ: Increased generation of Foxp3(+) regulatory $\mathrm{T}$ cells by manipulating antigen presentation in the thymus. Nat Commun 7: 10562, 2016.

25. Engel M, Sidwell T, Vasanthakumar A, Grigoriadis G and Banerjee A: Thymic regulatory $\mathrm{T}$ cell development: Role of signalling pathways and transcription factors. Clin Dev Immunol 2013: 617595, 2013.

26. Ouyang W, Beckett O, Ma Q, Paik Jh, DePinho RA and Li MO: Foxo proteins cooperatively control the differentiation of Foxp3 $3^{+}$ regulatory T cells. Nat Immunol 11: 618-627, 2010.

27. Kerdiles YM, Stone EL, Beisner DL, McGargill MA, Ch'en IL, Stockmann C, Katayama CD and Hedrick SM: Foxo transcription factors control regulatory $\mathrm{T}$ cell development and function. Immunity 33: 890-904, 2010.

28. Harada Y, Harada Y, Elly C, Ying G, Paik JH, DePinho RA and Liu YC: Transcription factors Foxo3a and Foxol couple the E3 ligase Cbl-b to the induction of Foxp3 expression in induced regulatory T cells. J Exp Med 207: 1381-1391, 2010.

29. Haribhai D, Williams JB, Jia S, Nickerson D, Schmitt EG, Edwards B, Ziegelbauer J, Yassai M, Li SH, Relland LM, et al: A requisite role for induced regulatory T cells in tolerance based on expanding antigen receptor diversity. Immunity 35: 109-122, 2011.

30. Omenetti S and Pizarro TT: The Treg/Th17 axis: A dynamic balance regulated by the gut microbiome. Front Immunol 6: 639, 2015.

31. Nitta T and Suzuki H: Thymic stromal cell subsets for T cell development. Cell Mol Life Sci 73: 1021-1037, 2016. 
32. Yarilin AA and Belyakov IM: Cytokines in the thymus: Production and biological effects. Curr Med Chem 11: 447-464, 2004.

33. Shitara S, Hara T, Liang B, Wagatsuma K, Zuklys S, Holländer GA, Nakase H, Chiba T, Tani-ichi S and Ikuta K IL-7 produced by thymic epithelial cells plays a major role in the development of thymocytes and TCR $\gamma \delta^{+}$intraepithelial lymphocytes. J Immunol 190: 6173-6179, 2013.

34. Tian T, Zhang J, Gao L, Qian XP and Chen WF: Heterogeneity within medullary-type TCRalphabeta(+)CD3(+)CD4(-)CD8(+) thymocytes in normal mouse thymus. Int Immunol 13: 313-320, 2001.

35. Chemin K, Bohineust A, Dogniaux S, Tourret M, Guégan S, Miro F and Hivroz C: Cytokine secretion by $\mathrm{CD}^{+} \mathrm{T}$ cells at the immunological synapse requires $\mathrm{Cdc} 42$-dependent local actin remodeling but not microtubule organizing center polarity. J Immunol 189: 2159-2168, 2012.

36. Coto JA, Hadden EM, Sauro M, Zorn N and Hadden JW: Interleukin 1 regulates secretion of zinc-thymulin by human thymic epithelial cells and its action on T-lymphocyte proliferation and nuclear protein kinase C. Proc Natl Acad Sci USA 89: 7752-7756, 1992

37. Dalloul A, Arock M, Fourcade C, Hatzfeld A, Bertho JM, Debré P and Mossalayi MD: Human thymic epithelial cells produce interleukin-3. Blood 77: 69-74, 1991

38. Galy AH, Dinarello CA, Kupper TS, Kameda A and Hadden JW: Effects of cytokines on human thymic epithelial cells in culture. II. Recombinant IL 1 stimulates thymic epithelial cells to produce IL6 and GM-CSF. Cell Immunol 129: 161-175, 1990.

39. Savino W, Mendes-da-Cruz DA, Lepletier A and Dardenne M: Hormonal control of T-cell development in health and disease. Nat Rev Endocrinol 12: 77-89, 2016

40. Savino W and Dardenne M: Neuroendocrine control of thymus physiology. Endocr Rev 21: 412-443, 2000.

41. Muegge K, Vila MP and Durum SK: Interleukin-7: A cofactor for $\mathrm{V}(\mathrm{D}) \mathrm{J}$ rearrangement of the $\mathrm{T}$ cell receptor beta gene. Science 261: 93-95, 1993.

42. Bayer AL, Yu A and Malek TR: Function of the IL-2R for thymic and peripheral $\mathrm{CD} 4{ }^{+} \mathrm{CD} 25^{+} \mathrm{Foxp}^{+} \mathrm{T}$ regulatory cells J Immunol 178: 4062-4071, 2007.

43. Varas A, Vicente A, Romo T and Zapata AG: Role of IL-2 in rat fetal thymocyte development. Int Immunol 9: 1589-1599, 1997.

44. Weist BM, Kurd N, Boussier J, Chan SW and Robey EA: Thymic regulatory $\mathrm{T}$ cell niche size is dictated by limiting IL-2 from antigen-bearing dendritic cells and feedback competition. Nat Immunol 16: 635-641, 2015.

45. Meilin A, Sharabi Y and Shoham J: Analysis of thymic stromal cell subpopulations grown in vitro on extracellular matrix in defined medium-v. Proliferation regulating activities in supernatants of human thymic epithelial cell cultures. Int J Immunopharmacol 19: 39-47, 1997.

46. Zlotnik A, Ransom J, Frank G, Fischer M and Howard M: Interleukin 4 is a growth factor for activated thymocytes: Possible role in T-cell ontogeny. Proc Natl Acad Sci USA 84: 3856-3860, 1987.

47. Shevach EM: Mechanisms of Foxp $3^{+} \mathrm{T}$ regulatory cell-mediated suppression. Immunity 30: 636-645, 2009.

48. Barnes MJ and Powrie F: Regulatory T cells reinforce intestinal homeostasis. Immunity 31: 401-411, 2009.

49. Mittal SK and Roche PA: Suppression of antigen presentation by IL-10. Curr Opin Immunol 34: 22-27, 2015.

50. Patel DD, Whichard LP, Radcliff G, Denning SM and Haynes BF: Characterization of human thymic epithelial cell surface antigens: phenotypic similarity of thymic epithelial cells to epidermal keratinocytes. J Clin Immunol 15: 80-92, 1995.

51. Meilin A, Shoham J, Schreiber L and Sharabi Y: The role of thymocytes in regulating thymic epithelial cell growth and function. Scand J Immunol 42: 185-190, 1995.

52. Baseta JG and Stutman O: TNF regulates thymocyte production by apoptosis and proliferation of the triple negative (CD3-CD4-CD8-) subset. J Immunol 165: 5621-5630, 2000.

53. Zúñiga-Pflücker JC, Jiang D and Lenardo MJ: Requirement for TNF-alpha and IL-1 alpha in fetal thymocyte commitment and differentiation. Science 268: 1906-1909, 1995.

54. Arzt E, Kovalovsky D, Igaz LM, Costas M, Plazas P, Refojo D, Páez-Pereda M, Reul JM, Stalla G and Holsboer F: Functional cross-talk among cytokines, T-cell receptor, and glucocorticoid receptor transcriptional activity and action. Ann NY Acad Sci 917: 672-677, 2000
55. Cohen-Kaminsky S, Delattre RM, Devergne O, Rouet P, Gimond D, Berrih-Aknin S and Galanaud P: Synergistic induction of interleukin-6 production and gene expression in human thymic epithelial cells by LPS and cytokines. Cell Immunol 138 : 79-93, 1991.

56. Wang J, Zhuo Y, Yin L, Wang H, Jiang Y, Liu X, Zhang M, Du F, Xia S and Shao Q: Doxycycline protects thymic epithelial cells from mitomycin C-mediated apoptosis in vitro via Trx2-NF-кB-Bcl-2/Bax axis. Cell Physiol Biochem 38: 449-460, 2016.

57. Shanley DP, Aw D, Manley NR and Palmer DB: An evolutionary perspective on the mechanisms of immunosenescence. Trends Immunol 30: 374-381, 2009.

58. Dooley J and Liston A: Molecular control over thymic involution: From cytokines and microRNA to aging and adipose tissue. Eur J Immunol 42: 1073-1079, 2012

59. Kappler JW, Roehm N and Marrack P: T cell tolerance by clonal elimination in the thymus. Cell 49: 273-280, 1987.

60. Xing Y and Hogquist KA: T-Cell tolerance: Central and peripheral. Cold Spring Harb Perspect Biol 4: pii: a006957, 2012.

61. Roberts JL, Sharrow SO and Singer A: Clonal deletion and clonal anergy in the thymus induced by cellular elements with different radiation sensitivities. J Exp Med 171: 935-940, 1990.

62. Kisielow P, Bluthmann H, Staerz UD, Steinmetz M and von Boehmer H: Tolerance in T-cell-receptor transgenic mice involves deletion of nonmature $\mathrm{CD} 4^{+} 8^{+}$thymocytes. Nature 333 : 742-746, 1988.

63. Ramsdell $\mathrm{F}$ and Fowlkes B: Clonal deletion versus clonal anergy: The role of the thymus in inducing self tolerance. Science 248 : $1342-1348,1990$

64. Nurieva R, Wang J and Sahoo A: T-cell tolerance in cancer. Immunotherapy 5: 513-531, 2013.

65. Xing Y and Hogquist KA: T-cell tolerance: Central and peripheral. Cold Spring Harb Perspect Biol 4: pii: a006957, 2012.

66. Wood KJ and Sakaguchi S: Regulatory T cells in transplantation tolerance. Nat Rev Immunol 3: 199-210, 2003.

67. Howard JK, Lord GM, Matarese G, Vendetti S, Ghatei MA, Ritter MA, Lechler RI and Bloom SR: Leptin protects mice from starvation-induced lymphoid atrophy and increases thymic cellularity in ob/ob mice. J Clin Invest 104: 1051-1059, 1999.

68. Wang SD, Huang KJ, Lin YS and Lei HY: Sepsis-induced apoptosis of the thymocytes in mice. J Immunol 152: 5014-5021, 1994

69. Müller-Hermelink HK, Sale GE, Borisch B and Storb R: Pathology of the thymus after allogeneic bone marrow transplantation in man. A histologic immunohistochemical study of 36 patients. Am J Pathol 129: 242-256, 1987.

70. Gruver AL and Sempowski GD: Cytokines, leptin, and stress-induced thymic atrophy. J Leukoc Biol 84: 915-923, 2008.

71. Boyd E: The weight of the thymus gland in health and disease Am J Dis Child 43: 1162-1214, 1932

72. Gruver AL, Hudson LL and Sempowski GD: Immunosenescence of ageing. J Pathol 211: 144-156, 2007.

73. Aw D, Silva AB and Palmer DB: Immunosenescence: Emerging challenges for an ageing population. Immunology 120: 435-446, 2007.

74. Fülöp T, Larbi A and Pawelec G: Human T cell aging and the impact of persistent viral infections. Front Immunol 4: 271, 2013.

75. Gruver AL, Ventevogel MS and Sempowski GD: Leptin receptor is expressed in thymus medulla and leptin protects against thymic remodeling during endotoxemia-induced thymus involution. J Endocrinol 203: 75-85, 2009.

76. Haynes BF, Markert ML, Sempowski GD, Patel DD and Hale LP: The role of the thymus in immune reconstitution in aging, bone marrow transplantation, and HIV-1 infection. Annu Rev Immunol 18: 529-560, 2000.

77. Billard MJ, Gruver AL and Sempowski GD: Acute endotoxin-induced thymic atrophy is characterized by intrathymic inflammatory and wound healing responses. PLoS One 6 : e17940, 2011.

78. Hick RW, Gruver AL, Ventevogel MS, Haynes BF and Sempowski GD: Leptin selectively augments thymopoiesis in leptin deficiency and lipopolysaccharide-induced thymic atrophy. J Immunol 177: 169-176, 2006.

79. Zhou YJ, Peng H, Chen Y and Liu YL: Alterations of thymic epithelial cells in lipopolysaccharide-induced neonatal thymus involution. Chin Med J (Engl) 129: 59-65, 2016.

80. Griffith Ann V, Venables T, Shi J, Farr A, van Remmen H, Szweda L, Fallahi M, Rabinovitch P and Petrie HT: Metabolic damage and premature thymus aging caused by stromal catalase deficiency. Cell Rep 12: 1071-1079, 2015. 
81. Dorshkind K, Montecino-Rodriguez E and Signer RA: The ageing immune system: Is it ever too old to become young again? Nat Rev Immunol 9: 57-62, 2009.

82. Gomez CR, Nomellini V, Faunce DE and Kovacs EJ: Innate immunity and aging. Exp Gerontol 43: 718-728, 2008.

83. Min D, Panoskaltsis-Mortari A, Kuro-o M, Holländer GA Blazar BR and Weinberg KI: Sustained thymopoiesis and improvement in functional immunity induced by exogenous KGF administration in murine models of aging. Blood 109: 2529-2537, 2007.

84. Rossi SW, Jeker LT, Ueno T, Kuse S, Keller MP, Zuklys S, Gudkov AV, Takahama Y, Krenger W, Blazar BR and Holländer GA: Keratinocyte growth factor (KGF) enhances postnatal T-cell development via enhancements in proliferation and function of thymic epithelial cells. Blood 109: 3803-3811, 2007.

85. Hsu HC, Zhang HG, Li L, Yi N, Yang PA, Wu Q, Zhou J, Sun S, $\mathrm{Xu}$ X, Yang X, et al: Age-related thymic involution in C57BL/6J $\mathrm{x}$ DBA/2J recombinant-inbred mice maps to mouse chromosomes 9 and 10. Genes Immun 4: 402-410, 2003.

86. Frawley R, White K Jr, Brown R, Musgrove D, Walker N and Germolec D: Gene expression alterations in immune system pathways in the thymus after exposure to immunosuppressive chemicals. Environ Health Perspect 119: 371-376, 2010.

87. Boehm T and Swann JB: Thymus involution and regeneration: Two sides of the same coin? Nat Rev Immunol 13: 831-838, 2013

88. Bluth MH, Kohlhoff S, Norowitz KB, Silverberg JI, Chice S, Nowakowski M, Durkin HG and Smith-Norowitz TA: Immune responses in autoimmune hepatitis: Effect of prednisone and azathioprine treatment: Case report. Int J Med Sci 6: 177-183, 2009.

89. Marchetti MC, Marco BD, Santini MC, Bartoli A, Delfino DV and Riccardi C: Dexamethasone-induced thymocytes apoptosis requires glucocorticoid receptor nuclear translocation but not mitochondrial membrane potential transition. Toxicol Lett 139: 175-180, 2003.

90. Gould KA, Shull JD and Gorski J: DES action in the thymus: Inhibition of cell proliferation and genetic variation. Mol Cell Endocrinol 170: 31-39, 2000.

91. Fletcher AL, Lowen TE, Sakkal S, Reiseger JJ, Hammett MV, Seach N, Scott HS, Boyd RL and Chidgey AP: Ablation and regeneration of tolerance-inducing medullary thymic epithelial cells after cyclosporine, cyclophosphamide, and dexamethasone treatment. J Immunol 183: 823-831, 2009.

92. Camacho IA, Singh N, Hegde VL, Nagarkatti $M$ and Nagarkatti PS: Treatment of mice with 2,3,7,8-tetrachlorodibenzo-p-dioxin leads to aryl hydrocarbon receptor-dependent nuclear translocation of NF-kappaB and expression of Fas ligand in thymic stromal cells and consequent apoptosis in $\mathrm{T}$ cells. J Immunol 175: 90-103, 2005.

93. Dudakov JA, Hanash AM, Jenq RR, Young LF, Ghosh A, Singer NV, West ML, Smith OM, Holland AM, Tsai JJ, et al: Interleukin-22 drives endogenous thymic regeneration in mice. Science 336: 91-95, 2012.

94. Larance M and Lamond AI: Multidimensional proteomics for cell biology. Nat Rev Mol Cell Biol 16: 269-280, 2015.

95. Leung EL, Cao ZW, Jiang ZH, Zhou H and Liu L: Network-based drug discovery by integrating systems biology and computational technologies. Brief Bioinform 14: 491-505, 2013.

96. Turiák L, Misják P, Szabó TG, Aradi B, Pálóczi K, Ozohanics O, Drahos L, Kittel A, Falus A, Buzás EI and Vékey K: Proteomic characterization of thymocyte-derived microvesicles and apoptotic bodies in BALB/c mice. J Proteomics 74: 2025-2033, 2011.
97. Billing AM, Revets D, Hoffmann C, Turner JD, Vernocchi S and Muller CP: Proteomic profiling of rapid non-genomic and concomitant genomic effects of acute restraint stress on rat thymocytes. J Proteomics 75: 2064-2079, 2012.

98. Schulze WX and Usadel B: Quantitation in mass-spectrometry-based proteomics. Annu Rev Plant Biol 61: 491-516, 2010.

99. Matt P, Fu Z, Fu Q and Van Eyk JE: Biomarker discovery: Proteome fractionation and separation in biological samples. Physiol Genomics 33: 12-17, 2008.

100. Sultana R, Di Domenico F, Tseng M, Cai J, Noel T, Chelvarajan RL, Pierce WD, Cini C, Bondada S, St Clair DK and Butterfield DA: Doxorubicin-induced thymus senescence. J Proteome Res 9: 6232-6241, 2010.

101. Ma C, Yue QX, Guan SH, Wu WY, Yang M, Jiang BH, Liu X and Guo DA: Proteomic analysis of possible target-related proteins of cyclophosphamide in mice thymus. Food Chem Toxicol 47: $1841-1847,2009$

102. Kawakami T, Nagata T, Muraguchi A and Nishimura T: Proteomic approach to apoptotic thymus maturation. J Chromatogr B Analyt Technol Biomed Life Sci 787: 223-229, 2003.

103. Tyanova S, Albrechtsen R, Kronqvist P, Cox J, Mann M and Geiger T: Proteomic maps of breast cancer subtypes. Nat Commun 7: 10259, 2016.

104. Chan PP, Wasinger VC and Leong RW: Current application of proteomics in biomarker discovery for inflammatory bowel disease. World J Gastrointest Pathophysiol 7: 27-37, 2016.

105. Peng F, Zhan X, Li MY, Fang F, Li G, Li C, Zhang PF and Chen Z: Proteomic and bioinformatics analyses of mouse liver microsomes. Int J Proteomics 2012: 832569, 2012

106. Goh WW, Lee YH, Chung M and Wong L: How advancement in biological network analysis methods empowers proteomics. Proteomics 12: 550-563, 2012

107. Miller JF: Immunological function of the thymus. Lancet 2: 748-749, 1961.

108. Burns JC and Franco A: The immunomodulatory effects of intravenous immunoglobulin therapy in Kawasaki disease. Expert Rev Clin Immunol 11: 819-825, 2015

109. Shankar-Hari M, Spencer J, Sewell WA, Rowan KM and Singer M: Bench-to-bedside review: Immunoglobulin therapy for sepsis - biological plausibility from a critical care perspective. Crit Care 16: 206, 2012.

110. Gupta M, Noel GJ, Schaefer M, Friedman D, Bussel J and Johann-Liang R: Cytokine modulation with immune gamma-globulin in peripheral blood of normal children and its implications in Kawasaki disease treatment. J Clin Immunol 21: 193-199, 2001

111. Chaudhry MS, Velardi E, Malard F and van den Brink MR: Immune reconstitution after allogeneic hematopoietic stem cell transplantation: Time to T Up the thymus. J Immunol 198: 40-46, 2017.

112. Zhu YX, Kortuem KM and Stewart AK: Molecular mechanism of action of immune-modulatory drugs thalidomide, lenalidomide and pomalidomide in multiple myeloma. Leuk Lymphoma 54: 683-687, 2013.

113. Ekins S, Gupta RR, Gifford E, Bunin BA and Waller CL: Chemical space: Missing pieces in cheminformatics. Pharm Res 27: 2035-2039, 2010.

114. Dobson CM: Chemical space and biology. Nature 432: 824-828, 2004. 